
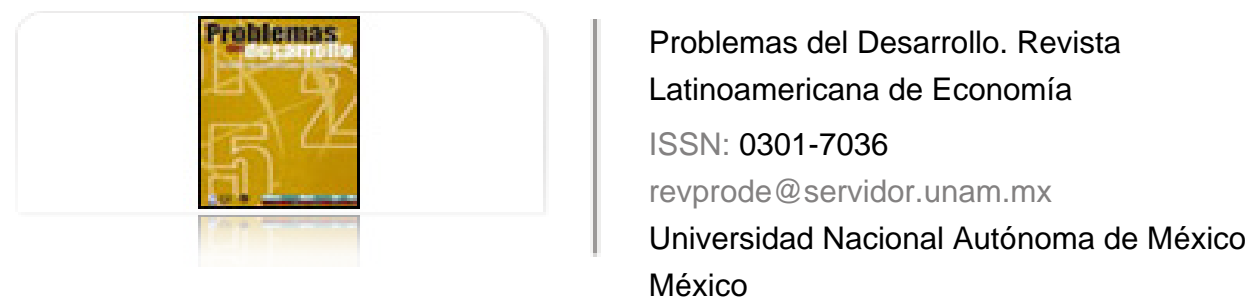

Vite Pérez, Miguel Ángel

La nueva desigualdad social

Problemas del Desarrollo. Revista Latinoamericana de Economía, vol. 38, núm. 148, enero-marzo, 2007, pp. 41-68

Universidad Nacional Autónoma de México

Distrito Federal, México

Disponible en: http://www.redalyc.org/articulo.oa?id=11820155003

Cómo citar el artículo

- Número completo

- Más información del artículo

Página de la revista en redalyc.org

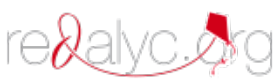

Sistema de Información Científica

Red de Revistas Científicas de América Latina, el Caribe, España y Portugal Proyecto académico sin fines de lucro, desarrollado bajo la iniciativa de acceso abierto 


\section{LA NUEVA DESIGUALDAD SOCIAL}

\section{Miguel Ángel Vite Pérez*}

Fecha de recepción: 6 de abril de 2006. Fecha de aceptación: 7 de septiembre de 2006.

\section{Resumen}

El propósito de este trabajo es analizar la pérdida del papel central del trabajo en un mundo de economía globalizada, donde las protecciones sociales, establecidas como derechos sociales y gestionados por un sistema estatal de bienestar, se han debilitado como consecuencia de la introducción de la mercantilización en los servicios sociales a partir de la consolidación de la politica económica neoliberal en diferentes países del orbe. Este hecho ha provocado una expansión de la desigualdad social, caracterizada por el empleo precario y los bajos ingresos, lo cual ha detenido la universalización de la política social, promoviendo programas de asistencia social para determinados grupos.

Palabras clave: desigualdad social, cuestión social, pobreza, Estado, asalariado.

\section{Abstract}

This study proposes to analyze the loss of the core role of work in a world of globalized economy, where social protections, established as social rights and managed by a state welfare system, have been weakened due to the commercialization introduced into the social services since the consolidation of neo-liberal economic policy in various countries around the world. This has led to the expansion of social inequality, characterized by precarious employment and low incomes, which has detained the universalization of social policy, promoting social assistance programs for certain groups.

Key words: social inequality, social question, poverty, State, wage-earners.

* Profesor -investigador del Centro de Investigaciones Económicas, Administrativas y Sociales (CIECAS) del IPN. Este trabajo se realizó con apoyo del CONACYT. Correo electrónico: miguelvite@yahoo.com 
Résumé

Le but de ce travail est d'analyser le fait que le travail perde le rôle central dans un monde d'économie globalisée, où les protections sociales, établies comme des droits et gérés par un système d'état providence, se sont affaiblies du fait de l'introduction du mercantilisme dans les services sociaux qui est le produit de la consolidation de la politique économique néolibérale dans divers pays du globe. Ce fait a provoqué l'expansion de l'inégalité sociale, caractérisée par l'emploi précaire et les bas revenus, qui ont stoppé l'universalisation de la politique sociale, en promouvant des programmes d'assistance sociale pour des groupes déterminés.

Mots clés: inégalité sociale, question sociale, pauvreté, État, salarié.

\section{Resumo}

O propósito deste trabalho é analisar a perda do papel central do trabalho num mundo de economia globalizada, onde as proteções sociais, estabelecidas como direitos sociais e gestadas por um sistema estatal de bem-estar, se debilitaram como conseqüencia da introdução da mercantilização nos serviços sociais a partir da consolidação da política econômica neoliberal em diferentes países do planeta. Este fato provocou uma expansão da desigualdade social, caracterizada pelo emprego precário e os baixos ingressos, o que deteve a universalização da política social, promovendo programas de assistência social para determinados grupos.

Palavras chave: desigualdade social, questão social, pobreza, Estado, assalariado. 


\section{A manera de introducción}

$C^{1}$

objetivo de este trabajo es explicar la nueva desigualdad social, con base en tienen en común la solidaridad generada por el trabajo y las instituciones estatales de protección social. ${ }^{1}$

El supuesto que se maneja es el siguiente: en las sociedades contemporáneas, la llamada cuestión social hace referencia a la crisis del contrato social, que permitió la integración de los grupos subalternos en las ventajas sociales gestionadas desde el Estado, considerando al trabajo o empleo como generador de derechos sociales (Dandurand, 1996).

La crisis de la sociedad del trabajo significa que el empleo asalariado ha dejado de ser el articulador de los derechos sociales, garantizados por las instituciones de bienestar social, dando paso a la precariedad, expresada en una multiplicación de las desigualdades que tienen diferentes orígenes, como grupo (raza), edad, discapacidad, sexo, entre otros.

Lo anterior ha sido resultado de la pérdida de la universalidad de las políticas sociales, que se han transformado en programas de asistencia social orientados a los grupos sociales clasificados como pobres extremos, para el caso mexicano, y en algunos países de Europa como personas en paro de larga duración.

Por otro lado, en México, desde un punto de vista general, la definición de la pobreza ha tenido como objetivo establecer una clasificación para determinar las familias que serán objeto de la ayuda estatal de tipo focal (Székely, 2005:19).

Pero no se toma en cuenta que la pobreza, como una manifestación de la desigualdad social, ha sido provocada por la expansión del desempleo y la precariedad laboral como resultado de la debilidad de los derechos sociales; mientras, el capital sigue abriendo nuevas fronteras económicas, ${ }^{2}$ donde las regulaciones estatales han

1 En este análisis, la protección social se vincula con el llamado Estado de bienestar o social (Castel, 2005:2).

2 La nueva guerra que promueve Estados Unidos y sus aliados europeos busca, más allá de la retórica de la libertad y del combate al terrorismo, abrir nuevos mercados para controlar las riquezas materiales de las naciones que se oponen a su dominio, llamado globalización económica (Chossudovsky, 2002a:65). 
sido abolidas, apoyado en un discurso ideológico que sostiene la idea de que el Estado debe estar libre de sus deberes en relación con sus ciudadanos, dejando de lado el cumplimiento de los objetivos de igualdad social. ${ }^{3}$

Sin embargo, el componente liberal de la democracia occidental no resultó ajeno a la estrategia de limitar el intervencionismo estatal, mostrando hostilidad hacia cualquier variante de colectivismo social. Sobre todo, sacralizó las contribuciones individuales y los derechos de propiedad por encima de los derechos colectivos; el descrédito de los políticos en favor de los empresarios y el aumento del poder de instituciones neutrales y técnicas, como las empresas y los bancos, a expensas del debilitamiento del Estado, pero fortaleciendo su papel como garante del proyecto económico neoliberal, con apoyo de las instituciones comerciales y financieras mundiales, que regulan algunos de los acuerdos económicos supranacionales. ${ }^{4}$

El nuevo modelo de acumulación transnacional ha renunciado explícitamente al principio de la igualdad social — garantizado por los servicios públicos producidos mediante la intervención del Estado-, lo que fue parte del componente solidario en una sociedad.

Por otro lado, la institución denominada partido se ha transformado en el medio principal para canalizar la acción social individualizada a través del voto, legitimando una representación parlamentaria partidista y plural, que armoniza el aspecto liberal de la democracia con el capitalismo.

Sin embargo, la tendencia a debilitar los derechos civiles y sociales — que ha permitido incidir en algunas consecuencias negativas de la desigualdad social-, también ha sido resultado del papel que el Estado ha desempeñado en los cambios introducidos en el reparto del poder económico y político en favor de una elite que:

bajo la égida de Estados Unidos, trabajando en conjunto con el [Fondo Monetario Internacional] y el Banco Mundial deberán de establecer "economías de libre mercado y sistemas democráticos [por ejemplo] en los países del sur del Cáucaso y el

3 El nuevo orden transnacional de los derechos de propiedad fue impulsado durante la administración del estadounidense Ronald Reagan, en la llamada Ronda de Uruguay. Su propósito era proteger las rentas de monopolio de las empresas de su país mediante un nuevo orden de los derechos de propiedad intelectual; estaba articulado también para que las compañías estadounidenses del sector servicios penetraran en otros países y establecieran operaciones con derecho a tratamiento nacional (Gowan, 2001:55).

4 El Estado, al convertirse en garante del proyecto económico neoliberal, ha intervenido, pero en favor de los grupos financieros o rentistas y, en el caso mexicano, ello se manifestó por medio del llamado rescate financiero, después de la crisis económica financiera de 1995 (véase Sandoval, 2005:594). 
Asia central [los cuales] proporcionarán incentivos a la inversión privada internacional, promoverán el comercio y otras formas de interacción comercial (Chossudovsky, 2002a:69).

Por eso, la internacionalización de la gestión económica neoliberal, apoyada por las instituciones financieras internacionales, ${ }^{5}$ se ha reflejado como una crisis de la función social del Estado (Esping-Andersen, 1993), ${ }^{6}$ afectando el carácter universal del bienestar colectivo, ${ }^{7}$ administrado por el Estado, pasando a ser más residual: solamente se prestaría a quien se necesita, ${ }^{8}$ es decir, para los que han sido considerados como individuos que no cuentan con los mínimos de bienestar ni con la autonomía necesaria para cumplir con los objetivos de éste. ${ }^{9}$

La problemática planteada presenta características comunes, como son las insuficiencias para crear solidaridad o cohesión social, lo que impide que las fracturas de una sociedad permitan su destrucción (Castel, 1995a:21). Sin embargo, en los

5 El BM y el FMI, en sus respectivos documentos, han integrado un discurso en favor de medidas económicas contra la pobreza; sin embargo, más allá de ser un discurso de legitimación, es una estrategia para que los países en desarrollo acepten las propuestas económicas neoli berales, al mostrarlas como la única opción para reducir los niveles de pobreza, mediante la ampliación de los mecanismos mercantiles en áreas donde su presencia es muy limitada (Cammack, 2002).

6 Cabe recordar que el Estado de bienestar, en la época de la posguerra, permitió menor desi gualdad debido a la existencia de un pleno empleo y al buen funcionamiento del mercado de trabajo; ello ciertamente ayudó a la consolidación de los derechos de la ciudadanía social. Sin embargo, no implica desconocer, por razones de análisis, la diferencia de los diversos es tados de bienestar respecto de su capacidad de protección ante los riesgos sociales causados por el desempleo y la discapacidad (Esping-Andersen, 2000:47).

$7 \quad$ El primer ministro británico Tony Blair señaló que el Estado de bienestar: "no puede ser un saco sin fondo [...] Cada vez hay más apoyo popular a la idea de que sirva sobre todo para atender a los más necesitados, para insertar a la gente, a cambio de un compromiso de ayudarse a sí mismos [...] El mensaje [según el periodista es] el seguir haciendo calar la idea de que el Estado de bienestar no es un derecho universal, gratuito e ilimitado, sino un instrumento puntual para ayudar a los más necesitados, acercándose así más al modelo norteamericano que al tradicional Estado asistencial centroeuropeo (subrayado del autor)" (Oppenheimer, 2002:2).

8 "Esto implica el querer imponer el punto de vista liberal acerca de la política social y con ello es remontarse [...] a la economía política británica del siglo XIX, concretamente a sus nociones de 'menor elegibilidad' y de 'autosuficiencia'. Dicha economía albergaba una fe ilimitada en la soberanía del mercado. En su forma contemporánea, los regímenes del bienestar liberales reflejan el compromiso político de minimizar el Estado, individualizar los riesgos y fomentar las soluciones de mercado. Por tanto, desfavorecen los derechos de los ciudadanos (subrayado del autor)" (Esping Andersen, 2000:103).

9 La autonomía se relaciona con el desarrollo de la capacidad del individuo para elegir opciones, administradas por las instituciones estatales, es decir, poder disfrutar de salud aceptable para elegir el tipo, por ejemplo, de educación, diversión, etcétera (Dahrendorf, 1994:189 197). 
apartados siguientes se destaca la importancia de la solidaridad, generada por el trabajo y los colectivos, protegidos por las políticas sociales (Castel, 1997a:48).

\section{El Estado de bienestar y la desigualdad}

El Estado de bienestar tiene su significado en el trabajo, debido a que el mismo fue una fuente importante de derechos y de bienestar, con la intervención de las instituciones estatales, reproduciendo la cohesión social.

Por tanto, la relación asalariada, es decir, la relación capital-trabajo, permitió que los sindicatos de obreros se transformaran en un sujeto importante en el proceso de formación del consenso político. "Dicho brevemente: el Estado [de Bienestar] fue solemnizado durante todo el periodo de la posguerra, como solución política de contradicciones sociales" (Offe, 1989:14).

Sin embargo, al final de la década de $1980^{10}$ apareció una inédita transformación en la geografía ideológica, que predominó durante el periodo de la llamada guerra fría, que significó el fin de los regímenes del "socialismo real" de la Europa central y del este, consolidando la globalización económica neoliberal. Por tal motivo, a las políticas públicas se les orientó más hacia el diseño de estrategias para la privatización de los servicios sociales, teniendo como pretexto la reducción del gasto social estatal e impulsando actitudes positivas hacia el mercado.

Sin embargo, la estabilización social, mediante el Estado de bienestar, en un sistema de producción capitalista no modificó las relaciones de propiedad, a pesar de que "el Estado [de Bienestar impuso] reglamentos administrativos y obligaciones al intercambio entre capital y trabajo en el ámbito de la producción” (Offe, 1989:15).

Lo anterior denota que el Estado de bienestar se organizó por medio de los mecanismos administrativos y de coerción:

[Dicho Estado] es así interpretado no como un mecanismo que se limita desde fuera a garantizar las condiciones de acumulación capitalista, sino como un sistema político que organiza, programa y controla el desarrollo económico a través de un

10 Se debe tener presente que en los años setenta, la crisis del Estado interventor en la producción y distribución del bienestar social se expresó como crisis fiscal, que los gobiernos conservadores de Estados Unidos y Reino Unido - Ronald Reagan y Margaret Thatcher, respectivamente-, utilizaron como excusa para establecer acciones de desregulación, mediante la mercantilización de diversos aspectos de dicho bienestar, garantizado por el Estado, con el pretexto de eliminar el déficit en el gasto público, apoyando a la inversión privada, transformada en el principal eje del desarrollo económico (véase O'Connor, 1981). 
conjunto multidimensional de instituciones políticas y administrativas (Picó, 1990:21)

Pero en un régimen cuya acumulación de capital se encuentra regulada estatalmente, ha provocado que las instituciones públicas sean el espacio donde se gesta una red de intereses vinculados a las funciones públicas del Estado (la producción de valores de uso); sin embargo, su función es selectiva respecto de las exigencias e intereses capitalistas (Offe, 1985).

De ese modo, la funcionalidad estatal fue en realidad una contradicción: “cómo un no capitalista — las instituciones estatales_ puede llegar a operar de un modo compatible con los requerimientos de la reproducción del capital" (Azuela y Duhau, 1987:50)

En el momento en que la contradicción señalada se manifiesta como una crisis económica, el punto de vista neoliberal estableció que el Estado de bienestar:

[Había] interrumpido o distorsionado los mecanismos de precios y utilidades como medio primario de asignación de la demanda y la oferta de artículos. Al desafiar a este medio, el Estado genera[ba] tanto un déficit permanente del presupuesto como nuevas demandas que, en cierto sentido, ha sancionado por medio de sus acciones afirmativas (Keane, 1992:44).

Pero la inequidad social surgida en el contexto dominado por el Estado de bienestar es resultado de la distribución funcional de los privilegios, que se vincularon a las necesidades de legitimación del sistema político. Ello quiere decir que la reproducción del sistema social no tuvo como fundamento principal al mercado, sino a la lógica política (Picó, 1990:62); una lógica criticada, desde el punto de vista neoliberal, ${ }^{11}$ una vez que entró en crisis el Estado de bienestar para presentar al mercado como la "única" solución a todos los problemas sociales (Marramao, 1982:24-25).

Sin embargo, la desigualdad social que se mantiene es resultado del funcionamiento del sistema capitalista, aunque conviva con una igualdad económica y política institucionalizada (Offe, 1992:49). Por eso la igualdad institucionalizada mediante la ciudadanía no pudo encubrir "la asimetría resultante de poder y libertad que surge entre los lados de la oferta y de la demanda desde el momento en que la

11 "Según está visión, la eficiencia de las intervenciones estatales depende de la selectividad [...] no erogación financiera en cascada, no subsidios sin límite, sino gasto social dirigido a objetivos limitados y específicos" (Millán, 2002:192). 
fuerza de trabajo es asignada a través de los mercados, es decir, tan pronto como se le trata institucionalmente como si fuera una mercancía, aunque de hecho no lo sea (Offe, 1996:51-52).

En otras palabras, es resultado de que el trabajo no solamente puede ser separado de su propietario, sino que el volumen, calidad, tiempo y lugar del salariotrabajo no se encuentran determinados estrictamente por la racionalidad mercantil, porque de ser así peligraría la vida de los trabajadores, por tanto, se hace necesario la presencia de mecanismos no mercantilizados de apoyo a su reproducción, como en su momento fueron las familias, comunidades y parroquias, una tarea que desempeñan los servicios sociales estatales (Polanyi, 2003:222-237).

En consecuencia, la crisis del Estado de bienestar también es resultado de su imposibilidad para mantener los mecanismos desmercantilizadores de la reproducción de los trabajadores, lo que ha dado paso a la introducción de la mercantilización, cuyos efectos se han manifestado como expansión de la precariedad laboral, donde la explotación no tiene más límites que el rendimiento y la eficiencia mercantil.

Por otro lado, Niklas Luhmann (1993) consideró que la crisis del Estado de bienestar fue resultado de un problema derivado de la insuficiencia de recursos económicos para satisfacer a un número creciente de demandas de los diversos grupos sociales. En otras palabras, la crisis es resultado de una "sobrecarga de demandas" (Marramao, 1982:154). Sobre todo, que "el sistema almacena las demandas satisfechas en la forma de derecho y dinero" (Luhmann, 1993:154).

Sin embargo, esta perspectiva no tomó en cuenta lo siguiente: las tendencias destructivas del mercado que se expresan como desempleo y subempleo, además de los conflictos sociales que surgen entre la economía capitalista y la organización política democrática (Offe, 1990:184).

En ese caso, la desigualdad social es considerada parte de la contradicción entre la mercantilización de la vida social y su desmercantilización mediante la producción de valores de uso, representados por el sistema de bienestar estatal. Aunque, desde la perspectiva liberal, se le confiere una funcionalidad para el sistema capitalista.

\section{La desigualdad y el liberalismo}

Ralf Dahrendorf (1995:133), desde una posición liberal, destaca el papel de las instituciones estatales como generadoras de oportunidades de vida - donde caben las libertades civiles, políticas y el bienestar colectivo-. Así, unen a los que inte- 
gran un orden social por normas y leyes, que proporcionan estabilidad, permitiendo a las instituciones establecer la estructura básica para acceder a los bienes materiales y simbólicos.

Pero la desigualdad social la interpreta como parte de los esfuerzos que cada individuo desarrolla para mejorar sus condiciones de vida; en ese sentido, la desigualdad es una fuente de esperanza e impulso hacia el progreso. Sin embargo, señala también la existencia de una desigualdad social disfuncional, vinculada con una distribución no adecuada de los ingresos:

a unos se les allana el camino hacia la cumbre, a otros se les trata de obstaculizar por medio de baches, zanjas o grietas. Las retribuciones de los sectores más acomodados de la población, los pertenecientes a los últimos 10 o 20 percentiles, están aumentando de manera significativa, al ritmo que descienden las retribuciones de las personas de los 20 o, quizá también, de los 40 percentiles más bajos (Dahrendorf, 1996:44).

Esa concentración de los ingresos ha creado una situación de exclusión en la cual parte de la población no tiene contacto con el mercado de trabajo, la comunidad política y la sociedad en general, y terminan por ser objeto de todo tipo de discriminaciones, cuya base puede ser la raza, la nacionalidad, la religión, acompañadas en determinadas coyunturas, por el uso de la violencia.

El desempleo y subempleo son dos manifestaciones de la falta de oportunidades para los individuos ${ }^{12}$ que no encuentran garantizado su nivel de vida en un orden social determinado ni por sus instituciones, lo cual ha provocado decadencia de los valores de compromiso social y, por tanto, no existe respeto a la ley ni a los valores que la han inspirado. ${ }^{13}$

En consecuencia, existe un peligro derivado del hecho de que las estructuras y normas no tengan la fuerza suficiente para ligar a los otros grupos, es decir, a los menos privilegiados, que también forman parte de la sociedad.

Por otro lado, desde una perspectiva funcionalista, la persistencia de la desigualdad social, según Tilly (2000), ha sido originada por la existencia de categorías

12 Las oportunidades de vida o vitales son: "en un sentido algo difuso, el conjunto de posibilidades u ocasiones que su sociedad o su posición social específica ofrecen al individuo. Probablemente, lo esencial aquí sean las posibilidades generalizadas" (Dahrendorf, 1983:50).

13 Pero esos valores son los relacionados con la justicia social sostenidos por el Estado de bienestar mediante la creación de un sistema de seguridad social, que tenía como finalidad la reducción de las situaciones de riesgo, causadas por el desempleo y las enfermedades (Véase, Bauman, 2001:93). 
—por ejemplo, hombre/mujer, negro/blanco, rico/pobre- que favorecen la explotación y el acaparamiento de oportunidades, mediante la ayuda de mecanismos como la emulación y la adaptación. Y, por eso, divide en dos las categorías: a) las internas, que limitan la organización misma, separando a los miembros de los no miembros, y $b$ ) las externas, que al margen de una organización dada, señalan las diferencias en las actividades, las retribuciones y donde el poder y las perspectivas, provienen de afuera:

La armonización de las categorías internas y externas fortalece la desigualdad dentro de la organización que la efectúa. La creación de un límite interior bien marcado facilita en sí misma la explotación y el acaparamiento de oportunidades al proporcionar explicaciones, justificaciones y rutinas prácticas para la distribución desigual de retribuciones (Tilly, 2000:89).

Ese límite interior se articula con las categorías externas como la de blanco/ negro, nacional/extranjero, por ejemplo, para reforzar la explotación y el acaparamiento de oportunidades. Esto también es posible por la emulación, con otras palabras, por la reproducción de modelos de organización que están presentes en otros lugares, así como por la adaptación, rutinas que ayudan a mantener las estructuras que permiten la desigualdad (Tilly, 2000:107-109).

Mientras, la política no se encuentra exenta de la explotación y acaparamiento de oportunidades por parte de las clases dirigentes, a pesar de la existencia de la democracia, porque no ha borrado la distinción entre inclusión y exclusión, que se refleja en el acceso a los bienes públicos, aunque una parte importante de la población puede acceder a los canales que permiten el paso de la exclusión a la inclusión. Eso no quiere decir que la desigualdad desaparezca en los países desarrollados, ya que los procesos económicos, al operar dentro de los límites fijados por las instituciones políticas y, en consecuencia, por las políticas públicas, reproducen asimetrías y privilegios controlados por medio de las categorías. Ese razonamiento circular no permite que se entienda la desigualdad social como un proceso histórico, que a pesar de su persistencia presenta ciertas peculiaridades, ello tampoco oculta el hecho de que las instituciones estatales no impiden del todo la reproducción de la desigualdad social.

\section{La desigualdad y la integración social}

En las sociedades contemporáneas, la integración social se ha alcanzado mediante el sistema de bienestar social administrado desde el Estado, que se articulaba con el 
trabajo asalariado porque la solidaridad generada era parte de los "mecanismos sociales por medio de los cuales las personas eran enseñadas y entrenadas en la práctica de la sociabilidad, de la reciprocidad y de la vida en común" (Tezanos, 2002:55).

La expansión de la mercantilización ha creado una fragilidad asociativa, manifestada como declive de la participación social en los procesos electorales y en las organizaciones vecinales y comunitarias.

De esta manera, la sociedad es concebida como un conjunto de instituciones orientadas por modelos de comportamiento estandarizados y asociados a papeles, que deben brindar apoyo, seguridad y referencias a quienes los desempeñan.

Por tal motivo, la incertidumbre instalada en el ámbito laboral ha actuado como un elemento disolvente para la adopción de una posición común, es decir, divide más que une, sobre todo, ahora que el empleo es temporal, porque las reglas relacionadas con la promoción y el despido han sido alteradas o abolidas.

No hay, por tanto, lealtad mutua y el compromiso desprendido de una dependencia recíproca de largo plazo entre el trabajador y el patrón, el lugar de empleo se ha transformado en uno que se visita por unos pocos días y meses, ya que el despido ha dejado de ser la excepción para convertirse en la regla. ${ }^{14}$ Ese proceso ha dado como resultado una sociedad más individualizada: los intereses comunes concretados con la presencia de los colectivos han perdido fuerza o han desaparecido, de tal manera que "temores, ansiedades y quejas [...] se padecen en soledad. No se suman, no se acumulan en una 'causa común', no tienen un 'domicilio natural' " (Bauman, 2001:35).

El mundo no presenta el aspecto de una totalidad conferida, en su momento, por una organización basada en la presencia del bloque capitalista y el comunista ya que una vez disuelto, el mundo parece un campo de fuerzas dispersas y desiguales con impulsos que nadie sabe detener (Bauman, 1999:79).

Pero es necesario mencionar que el orden mundial, mediante los dos bloques que existieron durante el periodo de la llamada guerra fría, fue mantenido por órdenes locales gestionados por el Estado-nación y, una vez disueltos, en algunos

14 A fines de 2005, las explosiones violentas de jóvenes franceses, descendientes de inmigrantes, en la periferia parisina y en otras provincias francesas no sólo tuvieron como objetivo la quema y destrucción de autos, sino algunas oficinas de empleo temporal. De esa manera mostraron que la posibilidad de mejorar su situación material en comparación con la de sus padres, mediante el empleo, se había evaporado (Chabrun et al., 2005:30 34). 
casos, se debilitó su capacidad de decisión en lo militar, lo económico y hasta en lo cultural.

Al mismo tiempo, existe una universalización de las normas del libre comercio, un proceso identificado con la globalización económica neoliberal que ha acelerado el movimiento del capital financiero (Chossudovsky, 2002b:17-18). Esto quiere decir que la economía se libera progresivamente del control político y solamente se le permite al Estado “mantener un 'presupuesto equilibrado' al reprimir y controlar las presiones locales en favor de una intervención más vigorosa en la administración de los negocios y en la defensa de la población ante las consecuencias siniestras de la anarquía del mercado" (Bauman, 1999:90).

En ese caso, la crítica se elabora en contra de la concepción neoliberal que olvida que la burocratización de los procesos sociales, la necesidad de la administración y planeación en las sociedades capitalistas ha provocado que las instituciones tengan un papel importante en la vida pública. Sobre todo, que algunas funciones sociales no son rentables para el capital, pero son necesarias para su desarrollo y tampoco pueden ser producidas de manera individual (Offe, 1999:64-65).

Sin embargo, el problema de la integración social se ha agudizado debido a que los intereses particulares y estrechos del capital se han vinculado con el Estado, limitando la institucionalización de un mecanismo regulador que garantice su autonomía relativa.

Dicha situación se intenta armonizar mediante la competencia entre partidos y el resto de las organizaciones sociales, en los cuales la legitimación, mediante símbolos políticos, intenta la configuración de consensos para establecer un equilibrio entre los requerimientos sistémicos de la acumulación de capital y de la reproducción de la misma sociedad.

En consecuencia, desde ese punto de vista, el grado de integración social no depende de los criterios abstractos de la acumulación de capital, sino de la legitimidad política que ha convertido a determinado número de carencias en objeto de atención de parte de un aparato asistencial estatal (Macpherson, 1991:87).

Pero el problema de la integración social se vincula con la forma en que se debería mantener la cohesión social, la solidaridad, que no se puede interpretar como un problema de conciliación entre los requerimientos de la acumulación con las demandas del electorado (Habermas, 1989), o como un problema que solamente tiene como origen la crisis fiscal (O’Connor, 1981), así como la desmercantilización de los valores de uso (Keane, 1992:201). 
La nueva desigualdad social tiene como problemas principales el trabajo y su pérdida de centralidad, en las sociedades modernas, es decir, la debilidad de los sistemas de protección social, lo cual ha favorecido la multiplicación de las desigualdades por género, raza, edad, condición migratoria, religión (Scott, 2005:80).

\section{La nueva desigualdad social}

La crisis de la relación asalariada, traducida en un incremento de los niveles del desempleo y subempleo, ha provocado que la mercantilización de los servicios sociales se instalara en las agendas de los gobierno neoliberales (Castel, 2001a:3748), provocando la pérdida del carácter universal de los derechos sociales (Castel, 1997b).

De ese modo, la lógica de mercado, desde un punto de vista general, se ha convertido en la institución principal que, como se ha señalado, debe articular la acción social (Bourdieu y Wacquant, 2000:4).

En ese sentido, la nueva desigualdad social forma parte del proceso de acumulación capitalista, guiado por los imperativos de la privatización y desregulación de la acción estatal en la esfera del bienestar colectivo (Paugam, 2000); además, de ser una forma de construir una nueva subordinación del trabajo a las necesidades del capital, pero sin costos que le pudiera representar la realización material de los derechos sociales (Castel, 2001a:42).

En el nuevo régimen de la desigualdad social, las responsabilidades estatales son mínimas y las del mercado inexistentes (Bourdieu y Wacquant, 2000:5; Blanc, 1998).

Por otro lado, los dueños de los negocios privados, con apoyo de los gobiernos neoliberales, han introducido la mercantilización de los servicios sociales administrados por el Estado de bienestar, impulsando el individualismo posesivo: hacer lo que uno mismo considera adecuado sin contribuir a su producción y, además, al Estado se le confiere solamente la misión de cuidar las posesiones y la seguridad física de sus dueños, lo cual se considera que forma parte del llamado Estado de derecho (Castel, 2005).

Eso también significa impulsar la función punitiva estatal: encerrar a los delincuentes en cárceles y mantener las calles "libres" de malhechores y mendigos (Bauman, 2001:60). Entonces, la expansión del desempleo y del subempleo ha dado como resultado una desigualdad social ${ }^{15}$ que ha dejado de tener como base el

15 "En América Latina [...] el aumento de la pobreza y de la desigualdad y la falta de redes de protección social adecuadas están conduciendo a la consolidación de democracias 
trabajo asalariado, teniendo como sustento su ausencia o precariedad, ${ }^{16}$ pero sin protecciones sociales (Therborn, 1992:19).

\section{La mercantilización y las instituciones multilaterales}

Bryson (1992) señaló la existencia de un discurso legitimador de la privatización de las funciones estatales desde las instituciones multilaterales. ${ }^{17}$ Por ejemplo, en 1980, la Organización para la Cooperación Económica y el Desarrollo (OCDE), organizó una conferencia llamada "La crisis del Estado de bienestar", donde a los países miembros se les presentó, como posibles soluciones a sus respectivas crisis económicas, medidas de gobierno orientadas hacia el mercado, considerando al sector privado como su principal protagonista.

Sin embargo, a fines de los años ochenta del siglo xx, después de la crisis del Estado de bienestar en los países desarrollados —al final de la década de 1970—, otra coyuntura crítica - la cual tuvo como base los eventos sucedidos en Europa central y del este, así como en la ex Unión Soviética— - se presentó como resultado de todo tipo de intervencionismo estatal (Bryson, 1992:11).

De ese modo, la privatización tomó nuevos impulsos, ya que se instaló en la agenda de los gobiernos de los ex regímenes del llamado "socialismo real". ${ }^{18}$

Así, la tendencia predominante fue que las empresas gubernamentales fueran vendidas a las compañías privadas, introduciendo la mercantilización en tareas como el cuidado de niños, de ancianos, en la provisión de pensiones, en la educación e incluso en la custodia de las prisiones; también en la prestación de servicios como la limpieza y la lavandería, sobre todo en hospitales y oficinas públicas, así como en el manejo del agua potable y en la residual.

representativas excluyentes, con una minoría de ciudadanos plenos, lo cual equivale a decir que se trata de regímenes políticos poco democráticos y poco representativos" (Nun, 2001:299).

16 "El riesgo de la precariedad y del desempleo ha generado [...] desigualdades profundas entre individuos que tienen la misma edad, el mismo nivel de diploma o la misma calificación [...] esto significa que las regulaciones colectivas se debilitan, que segmentos de la sociedad devienen débiles, debilitados y que un número creciente de individuos se encuentra desgajado de sus pertenencias colectivas" (Castel, 2001b:20 21).

17 "Existe una relación estrecha, casi 'simbiótica', entre las políticas de manejo de la deuda y las reformas macroeconómicas. El manejo de la deuda se reduce a garantizar que cada una de las naciones deudoras individuales continúe cumpliendo formalmente con sus obligaciones financieras" (Chossudovsky, 2002b:50).

18 De esa manera se instauró un orden económico internacional que se alimenta de la pobreza y, hasta cierto punto, de la mano de obra barata (Chossudovsky, 2002b:13). 
Estas acciones, en realidad, originaron mayor desigualdad social, ${ }^{19}$ porque las protecciones sociales fueron abolidas instalando la inseguridad social y el temor del mañana frente a la precariedad laboral (Rosanvallon, 1995a:7).

El Estado de derecho debería generar certidumbre y seguridad, como se ha mencionado, defendiendo los derechos de propiedad y de la vida, pero se ha olvidado también que la otra cara de la certidumbre se genera mediante el establecimiento de medidas positivas para la distribución de la renta, así como para la puesta en marcha de los servicios colectivos, lo cual se ha logrado, en un periodo reciente, después de la segunda guerra mundial, a través de un Estado providencia que: "debe entenderse como una radicalización, es decir, como una extensión y profundización del Estado protector ‘clásico' (Rosanvallon, 1995b:39)”.

La extensión y profundización del Estado protector fue también resultado de los movimientos sociales, que permitieron la expansión de los derechos de la ciudadanía para todos —el derecho al sufragio y el relacionado con la protección económica.

\section{Las compensaciones y la dinámica mercantil}

El derecho al trabajo y a la asistencia social, en un primer momento, colocaron las bases para la intervención estatal en la compensación de los efectos de cierta desarticulación social, provocada por el paro y la enfermedad.

Así, el Estado asumió como tarea la eliminación de las desigualdades, que dejaron de ser vistas como naturales y azarosas, teniendo como causa la misma dinámica económica capitalista. Y, en un segundo momento, el Estado providencia garantizó una abundancia mínima para todos los ciudadanos.

Sin embargo, la generalización del desempleo de larga duración ha provocado una situación en la cual el Estado providencia no puede proporcionar protección social, porque los riesgos han dejado de estar igualmente repartidos y no son aleatorios: "Se pasa así de un enfoque aleatorio y circunstancial de los 'desperfectos sociales' a una visión más determinista, en la cual se advierte la más débil reversibilidad de las situaciones de ruptura. Por ello mismo, todo un conjunto de poblaciones tiende a salir del campo asegurador" (Rosanvallon, 1995a:27).

19 El Reporte de la Situación Mundial de la Organización de las Naciones Unidas (ONU) de 2000 señaló que el libre comercio no es una alternativa eficaz, a menos que los gobiernos intervengan en la promoción del crecimiento y en la distribución equitativa de los recur sos (Pérez Ochoa, 2001). 
Y, en consecuencia, la inseguridad ligada a la pérdida del ingreso que el Estado providencia o de bienestar intentaba eliminar, ahora se le suma la inseguridad social derivada de la delincuencia, de las rupturas familiares y del terrorismo (Fitoussi y Rosanvallon, 1997:32-33).

Estas últimas se han convertido en la preocupación principal de los regímenes conservadores (tanto de derecha, como de tipo socialdemócrata) para que tienda a pedirse el retorno de un Estado protector de la vida y de la propiedad privada: un Estado modesto. ${ }^{20}$

\section{La exclusión social}

La exclusión social también forma parte de la nueva cuestión social, relacionada con el estatuto del asalariado (Castel, 1997b:389), en la cual la presencia del Estado paliaba las disfunciones que hacían peligrar la cohesión social.

Por eso el objetivo estatal fue el de mejorar las condiciones de vida de todos, disminuyendo las consecuencias indeseables del funcionamiento de la lógica del mercado y de la ganancia capitalista.

Ello tuvo un efecto homogenizador al atender las contingencias de una manera general sin tener en cuenta las particularidades de los individuos, lo cual pudo realizarse por la existencia de categorías jurídicas abstractas, que al considerar al individuo como miembro de un colectivo tenía derechos de protección de los inconvenientes producidos por la vejez, el desempleo, la incapacidad física, entre otros. En otras palabras, de los efectos perturbadores creados por el mismo proceso de acumulación capitalista (Silver, 1994:531-532). ${ }^{21}$

La condición salarial se articulaba con el derecho al trabajo y la protección social, que tendría efectos favorables sobre una disminución de las desigualdades. Pero en la década de 1970, con la llamada crisis del Estado de bienestar, ${ }^{22}$ no solamente se

20 Un Estado modesto no es omnipresente ni omnicompetente ni, por tanto, puede garantizar totalmente el funcionamiento de los servicios colectivos, ya que su prestación depende de las colectividades locales o de organismos autónomos especializados (Crozier, 1995:56).

21 "Las tendencias recientes hacia la privatización y la reestructuración del Estado de bienestar están teniendo lugar principalmente, aunque no de forma exclusiva, en el área de la producción de servicios esenciales para la calidad de la reproducción social, que son, en general, la sanidad, el transporte público y las infraestructuras urbanas, incluida la vivienda (Mingione, 1993:277).

22 No cabe duda que la crisis del Estado de bienestar puso en evidencia sus limitaciones, por ejemplo, al fomentar el empleo de las mujeres no eliminó su discriminación, un hecho que entra en contradicción con el ímpetu universalista promovido por el desarrollo de los 
detuvo la trayectoria de consolidación del asalariado, sino que se rompió la asociación entre trabajo y protecciones sociales (Castel, 2001a:38-41).

Entonces, el riesgo del paro y la precariedad se generalizó y empezó con ello otro proceso: la llamada descolectivación de las condiciones de trabajo y de las formas de organización de los trabajadores. Es decir, la individualización del riesgo y la precariedad.

El peligro radica en el incremento de individuos que no solamente viven en una situación de precariedad laboral y de inseguridad ( $c f r$. Sennett, 2000), sino de desafiliación: individuos sin ningún vínculo, a semejanza de un vagabundo, con los colectivos (Castel, 1997b:468).

Resulta entonces más preciso hablar de desafiliación y no de exclusión social, el debilitamiento o fragilización de los lazos de cohesión social, sobre todo, que nadie vive fuera de una sociedad.

Entonces, la nueva desigualdad social conduce a la desafiliación o a la exclusión, que tienen su origen en la pérdida de capacidad de integración social, de parte del empleo estable, dando paso a la generalización de un empleo precario y vulnerable, sin contar con redes familiares o sociales de protección. En otras palabras, significa la ruptura de la cohesión social o de la llamada solidaridad social y la fragmentación de las relaciones sociales, iniciando la época del posbienestar, caracterizada por la existencia de servicios privatizados con un sector público reducido:

Las propias políticas sociales de algunos gobernantes, en lugar de reforzar el núcleo de la economía o prestar mayor atención efectiva hacia sectores de la población doblemente penalizados, están fomentando la informalización y el desarrollo de modalidades irregulares de trabajo en diversos aspectos (Mingione, 1993:284).

Por otro lado, la solidaridad social que emana de un orden moral y normativo, externo al individuo, y que sirve para ligarlo a la sociedad por medio de mecanismos institucionales, en caso de debilitarse, no solamente provocaría la anomia que amenazaría la cohesión social (Durkheim, 1993, vol. 1:57-65), sino que mostraría el agotamiento del principal mecanismo de integración social en las sociedades capitalistas: el trabajo, es decir, la relación asalariada (Durkheim, 1993, vol. 2:7-29).

sistemas de bienestar, el elevado costo que supone proporcionar servicios de bienestar social sobre una base universalista, es decir, mantener y elevar la calidad de los servicios; tampoco se pudo eliminar del todo la discriminación, así como la sobrecarga debida al exceso de demanda (Mingione, 1993:279 281). 
En el caso del liberalismo angloamericano, basado en la sociología funcionalista (véase Girola, 1996), la exclusión social fue considerada consecuencia de la especialización: de la diferenciación social, de la división del trabajo y de la separación de la sociedad en diferentes esferas que, al mismo tiempo, habían creado estructuras de cooperación y de competencia individual. Pero la exclusión resultaba de una inadecuada separación de las esferas sociales, de la aplicación de reglas inapropiadas en el funcionamiento de las mismas o de la existencia de barreras para el libre movimiento y de las limitaciones para permitir el libre intercambio entre las diferentes esferas.

La exclusión social también ha sido vista como consecuencia de la formación de grupos de monopolio, es decir, el orden social es coercitivo e impuesto mediante relaciones jerárquicas de poder sustentadas, en realidad, en el monopolio que algunos grupos sociales ejercen sobre los recursos escasos, lo cual se puede evitar en la medida en que se extienda la ciudadanía, permitiendo que los beneficios materiales lleguen a la mayor parte de los grupos excluidos de los mismos. ${ }^{23}$

\section{El consumo masivo}

La masificación del consumo no sólo tuvo como fundamento el modelo de producción fordista, sino la existencia de un mecanismo político de integración en una realidad social conflictiva, un modo de regulación que, actuando bajo la lógica de los principios de igualdad entre los individuos, ${ }^{24}$ sería compatible con las desigualdades funcionales del capitalismo. Dicho mecanismo político fue el Estado de bienestar o providencia que pudo conjugar la igualdad democrática con los sistemas de protección social y los derechos sociales (Dubet, 2000:15).

Este modelo de organización social permitió la masificación del consumo, lo cual generalizó ciertas formas de distinción aristocrática, mediante el acceso a determinados bienes y servicios (véase Wirth, 1988), que en su momento fueron de consumo exclusivo de una minoría que finalmente servía para diferenciarse del resto (Bourdieu, 1991:20-21).

23 Se supone que, en las sociedades capitalistas desarrolladas, el concepto de ciudadanía conlleva la idea de igualdad que socava la desigualdad basada en privilegios y monopolios en la medida en que ha institucionalizado derechos políticos, civiles y sociales (cfr. Marshall, 1998:36 50).

24 La pasión por la igualdad que observó Tocqueville en Estados Unidos en realidad fue posible por un acceso mayor de la población estadounidense a la mayoría de los bienes y servicios que, en determinadas circunstancias, eran símbolo del ascenso social (Tocqueville, 1969: 54 57). 
Pero esa masificación en el acceso de bienes y servicios, prestados o no por el Estado, significó también la adopción generalizada de los estilos de vida pertenecientes a las clases medias, dando la impresión de su democratización; sin embargo, no pudo evitar la segregación. Es decir, los individuos pertenecientes a las clases superiores siguieron concentrando las oportunidades que les permitían conservar sus privilegios y ventajas sociales.

El modelo de integración social basado en las protecciones sociales estatales hizo posible que la pobreza dejara de ser un problema individual para transformarse en uno social, un problema de interés social, donde la intervención política fue de suma importancia.

\section{La desigualdad como problema social}

La desigualdad fue vista como un problema para el orden social, contradiciendo la noción de igualdad, perteneciente a la organización política democrática.

En otras palabras, la lógica política estaba en contradicción con la lógica del mercado y eso favoreció el surgimiento del marco institucional necesario para abordar el problema de la pobreza, independientemente de sus implicaciones económicas y políticas y, en consecuencia, "[emergió] una base racional para el control de los problemas de desigualdad en una sociedad de iguales" (Procacci, 1999:20).

La desigualdad se convertía en un problema social que debería ser regulado de manera institucional debido a la socialización del riesgo. Otra vez, esa regulación institucional provenía de la administración estatal, al poner en marcha políticas sociales que intentaron superar las tensiones existentes entre el liberalismo político y los principios solidarios; más tarde, en los países desarrollados esta situación favoreció para que los derechos sociales adquirieran la misma legitimidad que los civiles y políticos. Y, de ese modo, los derechos sociales se volvieron parte del estatus de la ciudadanía: el derecho universal a una renta no sujeta al valor de mercado para la mayoría (Marshall, 1998:52).

El Estado de bienestar, ${ }^{25}$ como modelo de integración social, basado en la relación asalariada y articulado a las protecciones estatales, permitió la consolidación

25 Desde una posición liberal, la generalización de la igualdad, al menos en los países desarrollados, con la ayuda de los mecanismos gubernamentales de administración del bienestar colectivo, tuvo problemas en la medida en que intentó introducir el principio de igualdad en los bienes derivados de la posición que se ocupa en la estructura social, por ejemplo "No es posible que todos tengan un chalé con vistas a un lago maravilloso en la montaña, porque si cada uno poseyera uno semejante ninguno vería ya el lago de la montaña, sino que lo único que 
de la ciudadanía en el siglo xx; sin embargo, con su crisis ha favorecido la generalización del paro y la precariedad, pero también desde el ámbito político, donde las administraciones gubernamentales conservadoras han centrado más su interés en los aspectos civiles y políticos de la ciudadanía, ${ }^{26}$ dejando de lado el aspecto social sin considerar la pobreza como problema social, sino individual o de falta de vínculos con la esfera mercantil, donde la competencia y la eficiencia determinan el triunfo o el fracaso de los individuos.

Pero lo que en realidad ha sucedido es el colapso de los sistemas de regulación del periodo de la posguerra, que se ha expresado como una crisis del capitalismo. Este hecho ha balanceado las relaciones de poder en favor del capital financiero y transnacional, que ha encontrado su legitimación en la ideología neoliberal (Montes, 1996:51-74), cuyos elementos constitutivos son: la disminución del gasto público para reducir el déficit estatal, la privatización y desregulación, políticas monetarias que fijen las tasas de interés por arriba de la inflación (Amin, 2000:47).

Sin embargo, esas acciones solamente han beneficiado a la inversión financiera a costa de la inversión productiva, lo cual ha terminado por fortalecer la estrategia de la libre flotación de las tasas de cambio (lo cual favorece a la especulación); mientras, el manejo de la deuda de los países del tercer mundo y de los que integraban el bloque ex socialista de Europa del este solamente ha sido para asegurar su pago a costa de sacrificar su desarrollo. Eso ha sido supervisado por el FMI y el BM, que a partir de 1990 han presionado a los gobiernos de los países endeudados para liberalizar las transferencias.

Las consecuencias de ese proceso estructural se han manifestado en el incremento de la pobreza, la disolución de los lazos sociales, la exclusión y la marginalización de países; pero también en las naciones capitalistas centrales se ha instalado la inseguridad laboral y el desempleo permanente.

verían todos serían los otros chalés. No todos pueden ser presidentes de la república, porque por definición hay un solo presidente de la república" (Dahrendorf, 1993:84).

26 La ideología neoliberal pudo tener la fuerza política y académica por la proliferación, a partir de los años ochenta del siglo xx, de un conjunto de instituciones privadas dedicadas a fundamentar las medidas de los gobiernos conservadores y socialdemócratas que buscaron la privatización de las empresas públicas, la desregulación económica y la misma precariza ción laboral (Dixon, 1998:17 y ss; Bourdieu, 1999:11 22). 


\section{La desarticulación del conflicto capital-trabajo}

La desarticulación de la institucionalización del conflicto entre el capital y el trabajo mediante el Estado de bienestar (Giddens, 1996:382) se aceleró al introducir, como principio organizativo de las relaciones sociales, la competencia mercantil, lo que ha favorecido el proceso de desafiliación y, por tanto, de exclusión social.

Eso significa que el proyecto de los países capitalistas centrales de la economíamundo para domesticar o controlar a sus propias clases trabajadoras por medio de un programa basado en el sufragio universal, el bienestar social y la identidad nacional, tiene ahora limitaciones para su realización, y en los países de la periferia dicho proyecto solamente ha tenido una vigencia acotada a los grupos privilegiados (Wallerstein, 1996:18-22).

Entonces, como el Estado ha limitado su intervención en la administración del bienestar social, se considera que lo político se vuelve neutral y lo mismo es válido para la esfera de la economía, ${ }^{27}$ con ello se supone que se estaría recuperando el “'sano egoísmo' que dio lugar al nacimiento y auge del capitalismo" (Cortina, 1998:71).

De ese modo se da paso a una institucionalización de la eficiencia y la competitividad, que respeta la libertad individual y la libre iniciativa. Por tanto, al renunciar al valor de la igualdad, se reduce la desigualdad social a problema individual y de resolución mediante el mercado y el crecimiento económico. ${ }^{28}$

\section{La nueva gobernabilidad}

La desregulación estatal es una autolimitación para que las fuerzas asociadas con el mercado tengan un mayor protagonismo ante los electores sin grandes limitaciones originadas por las instituciones políticas. "La tendencia más marcada de nuestra época es la separación del poder y la política: el verdadero poder, que es capaz de determinar el alcance de las elecciones prácticas, fluye, gracias a su movilidad

$27 \quad$ La idea del mercado como mecanismo neutral proviene de la aspiración a eliminar lo pasional en las relaciones sociales y las respuestas violentas que respondan solamente a la fuerza, por tanto, es la "mano invisible", no personalizada, un modo de regulación abstracto, lo que significa que una sociedad ha dejado de ser tradicional y es más moderna (cfr, Rosanvallon, 1989).

28 El crecimiento económico, al ser gestionado por las elites, termina por beneficiarlas, sin embargo, en países donde los "frutos" del desarrollo se encuentran concentrados frente a una masa empobrecida y sin que dicho patrón sufra modificación, esa situación no se revierte y trae como resultado que la desigualdad social se agudice (cfr. Tortosa, 2001). 
—nunca tan irrestricta_, es virtualmente global... o más bien, extraterritorial" (Bauman, 2002:82-83).

Entonces, el Estado ejerce el rol tradicional de control de los grupos sociales que han quedado fuera de la agenda establecida por el mercado y que viven al margen de la misma; mientras, para el resto, sus opciones se localizan fuera del interés de las autoridades políticas.

En ese sentido, la lógica política se encuentra neutralizada por las fuerzas del mercado, y contra ellas el político actual no puede hacer nada porque ha asumido como propio el vocabulario empresarial, ${ }^{29}$ es decir, mediante palabras como privatización y competencia se ha reducido la gobernabilidad a un problema técnico relacionado con la calidad y la economía (Guerrero, 1999).

Desde esa perspectiva, la crisis de gobernabilidad tiene como causa la lógica política que institucionalizó acuerdos sociales mediante el Estado de bienestar. Pero en realidad se trata de una crisis cuya causa se debe a que, en las sociedades capitalistas, se ha intentado hacer compatible la lógica de la producción capitalista, su carácter privado, con la de su socialización, su politización; en otras palabras, hacer coincidir las normas y valores de los miembros de una sociedad con las condiciones sistémicas de funcionamiento a las que están sometidas (Offe, 1996:49).

Entonces, la solución que presentan los partidarios del mercado es la siguiente: las actuaciones y comportamientos de los individuos deben concordar con los imperativos funcionales del mercado.

Dicho de otra manera, las reglas y normas que rigen los comportamientos de los individuos deben ser compatibles con las de la lógica de la acumulación capitalista para, según los apologistas del mercado, impedir las disfunciones y la crisis de gobernabilidad.

En términos de Robert Castel (2000:526-527), el imperativo de vincular las normas y los comportamientos sociales a la lógica mercantil o sistémica de tipo capitalista ha acelerado el proceso de desafiliación, debido a que la zona de integración fuertemente ligada al Estado de bienestar se ha debilitado y, en consecuencia, la desafiliación ha dejado su posición marginal. Sin embargo, la vulnerabilidad se intercepta con la inseguridad laboral, provocando una fragilidad en los lazos sociales (Castel, 1995b:27-36).

29 El mundo se encuentra dominado por mercados que no sólo controlan los bienes y servicios materiales, sino la cultura y la personalidad (Touraine, 2000:38). 
Al generalizarse el desempleo y subempleo, la desestabilización del trabajo ha comenzado a erosionar una de las bases de la integración social, junto con las protecciones sociales gestionadas por el Estado; mientras, la otra, representada por la familia, también ha dejado de ser un factor de integración social más cercano a la protección personal, donde se comparten, en un mismo espacio, valores de solidaridad, los cuales permiten el surgimiento de redes de mutua responsabilidad. Redes que se vuelven frágiles con la desestabilización introducida en la relación asalariada, que ha constituido un mundo social con sus significados y sus estructuras sociales que lo mantienen (Bourdieu, 2001:55).

La subordinación del trabajo a la lógica sistémica capitalista ha implicado coacciones donde la violencia se apoya en una relación de fuerza bajo la amenaza del despido y el temor unidos a la precariedad de la posición que se ocupa. Dicha circunstancia violenta el estatus del empleo asalariado, porque los derechos sociales que conlleva lo ha convertido en un derecho, al menos en las sociedades capitalistas centrales y democráticas (Schnapper, 1997:205).

Así, la ciudadanía ha perdido su base material para fragmentarse y tener como referente lo cultural, lo étnico, lo ecológico, el consumo y, de esa manera, articula solamente demandas particulares, lo cual significa que el trabajo ha dejado de ser el eje organizativo de la sociedad y de la ciudadanía mediante las protecciones sociales estatales (Urry, 1999:314).

Esa situación también significa la expansión de los mecanismos mercantiles hacia aspectos de la vida social que eran administrados con la lógica del Estado de bienestar, y que han encontrado su apoyo en las corporaciones económicas transnacionales y los organismos multilaterales, de carácter comercial y financiero, que han internacionalizado un modelo en el cual se exige el flujo del capital financiero con mínimas restricciones estatales (Marcuse, 2001:2).

\section{Reflexiones finales}

La importancia de este trabajo se deriva del hecho de que su dimensión legal, integrada mediante un sistema de derechos y deberes determinados por su utilidad colectiva y no solamente por la de las transacciones mercantiles, alcanzó - mediante la ciudadanía - a gran parte de los miembros de una sociedad.

Y esa dimensión legal del trabajo pudo mitigar los efectos negativos de una subordinación del trabajo al capital, al reducir, por ejemplo, el poder arbitrario de los empleadores, lo que se reflejó en salarios por arriba del nivel de subsistencia, 
gracias también a la protección social, y al mismo tiempo lo dignificó al transformarlo en una fuente de derechos (Castel, 1996:619-620).

Por su parte, en algunas coyunturas, el Estado-nación ha sufrido un proceso de "desestructuración", donde el riesgo de la radicalización y del choque de identidades culturales es una realidad ya que las mediaciones institucionales y políticas tienen una escasa influencia para evitarlas.

Así, lo social fue inventado para contribuir al mantenimiento del orden, de la estabilidad, ligada a los derechos ciudadanos, donde el bienestar resulta importante (Donzelot, 1994).

A pesar de que la globalización económica introduce la idea de una cierta unidad, económica y financiera, del mundo en el cual se vive, al mismo tiempo ha aparecido la pluralidad y la diversidad de las formas culturales y sociales, que la misma ha engendrado o reforzado (Wieviorka, 2000:19-20).

Sin embargo, frente a la pérdida de la capacidad de integración del Estadonación se ha buscado su sustituto en la de asociación de los integrantes de una sociedad. ${ }^{30}$ Es decir, en su capital social ${ }^{31}$ redes sociales que facilitarían la coordinación de acciones colectivas, y con ello se buscaría paliar los aspectos negativos del mismo proceso de globalización económica (Lechner, 2002:91).

Pero lo anterior no ha podido consolidar nuevos dispositivos que restauren el daño causado por la expansión del paro y la existencia de una probabilidad elevada de que la exclusión social, según Robert Castel (2004:74-75), siga siendo no una excepción, sino la norma en las diferentes sociedades capitalistas, porque quien tenga empleo, con protecciones sociales, es ahora un privilegiado. ${ }^{32}$

30 A raíz de los acontecimientos políticos de la década de 1980, sucedidos en Europa del este y central, relacionados con la organización de una oposición social en contra de las burocracias de los regímenes del llamado socialismo "real", se comenzó a popularizar la noción de sociedad civil, al menos en las democracias occidentales, para hacer énfasis en el valor comunitario de la libertad política, más que a su aspecto legal; sin embargo, desde la perspectiva neoliberal se ha usado para reivindicar el aspecto "creativo" de la sociedad frente a un Estado nación burocrático y autoritario (véase Honneth, 1996:30).

31 La noción de capital social alude a la confianza social, normas de reciprocidad, al compromiso cívico en una asociación de individuos con la finalidad de coordinar acciones colectivas (Putnam, 1993).

32 En Francia, la rebelión juvenil contra el Contrato del Primer Empleo, en el cual se establece que después de dos años la patronal puede despedir a un empleado juvenil de hasta 26 años sin justificación alguna, revela la crisis del empleo, pero también es un golpe a su dignidad, porque el patrón puede usarlos y botarlos, después de 24 meses, sin importar sus diplomas o títulos académicos (Mergier, 2006:58). 
La realización de los derechos sociales por medio del trabajo asalariado, con las protecciones estatales, englobadas con la palabra de bienestar social, permitió que la desigualdad social no se expandiera y atentara contra la solidaridad, porque los lazos con los diferentes colectivos proporcionaban una estabilidad social, así como atender las consecuencias sociales de la marcha de la economía capitalista, expresadas mediante las situaciones de vulnerabilidad como el desempleo, la pobreza, la enfermedad, entre otros.

La individualización de los riesgos de la vulnerabilidad ha provocado que la nueva desigualdad social sea múltiple, es decir, con la ausencia o debilidad de las protecciones sociales ha favorecido que tenga como causa la edad, el sexo, la raza, el estado civil.

Por otro lado, se ha perdido de vista que la mercantilización de la vida social tiende a destruir a la misma sociedad, porque en nombre de la eficiencia y de la productividad no importa que los trabajadores pierdan sus capacidades, que no pueden ser compensadas, ya que los servicios sociales solamente se prestan siguiendo los criterios de la oferta y la demanda.

La realización de la utopía del libre mercado supone que las instituciones estatales no sean un obstáculo para la acumulación de las ganancias privadas, cuando en realidad son protecciones sociales que sirven para limitar sus efectos devastadores.

No se intenta regresar al pasado, sin embargo, se ha destacado que la manera de intervenir en los efectos negativos de la marcha del mercado sobre los individuos ha sido mediante las protecciones sociales, dispositivos que tienen su propia historia, así como la importancia que adquirió el trabajo asalariado para las sociedades democráticas que buscaban el cumplimiento de los propósitos de igualdad social.

Bibliografía

Amin, Samir, Economic, Globalism and Political Democratic Universalism: Conflicting Issues?, México, Coordinación de Humanidades, UNAM, 2000.

Azuela, Antonio y Emilio Duhau, "De la economía política de la urbanización a la sociología de las políticas urbanas", Sociológica, núm. 4, México, UAM-A, enero-abril de 1987, pp. 40-69. Bauman, Zygmunt, En busca de la política, $\mathrm{FCE}$, Buenos Aires, 2002.
, La sociedad individualizada, Madrid, Cátedra, 2001.

- La Globalización. Consecuencias Humanas, Fondo de Cultura Económica, Sao Paulo, 1999.

Blanc, Maurice, "Social integration and exclusion in France: Some introductory remarks from a social transaction perspective", Housing Studies, vol. 13, núm. 6, Londres, 1998, pp. 781-792. 
Bourdieu, Pierre y Löic Wacquant, Neoliberal Newapeak: Notes on the New Planetary Vulgate, Londres, mimeo, 2000.

Bourdieu, Pierre, "La doble verdad del trabajo", Archipiélago, núm. 48, Madrid, enerofebrero de 2001, pp. 53-56.

, Contrafuegos. Reflexiones para servir a la resistencia contra la invasión neoliberal, Barcelona, Anagrama, 1999.

_ La distinción. Criterio y bases sociales del gusto, Madrid, Taurus, 1991.

Bryson, Lois, Welfare and the State, Hong Kong, MacMillan, 1992.

Cammack, Paul, "Ataque a los pobres a escala global”, New left review, núm. 13, Barcelona, 2002, pp. 104-112.

Castel, Robert, Estado e inseguridad social, Buenos Aires, Subsecretaría de la Gestión Pública, 2005.

, "La sociologie et la réponse á la demande sociale", Bernard Lahire (coordinador), $A$ quoi sert la sociologie?, Paris, Éditions La Découverte, 2004.

, ¿Por qué la clase obrera ha perdido la partida?", Archipiélago, núm. 48, Madrid, 2001a, pp. 37-48,

, "Empleo, exclusión y las nuevas cuestiones sociales", Alain Touraine et al., Desigualdad y Globalización. Cinco Conferencias, Buenos Aires, Facultad de Ciencias Sociales (Universidad de Buenos Aires)-Manantial, 2001b.

, "The Roads to Disaffiliation: Insecure Work and Vulnerable Relationships", International Journal of Urban and Regional Research, vol. 24, núm. 3, Washington, 2000, pp. 519-535.

, "Centralidad de la cuestión social. Conversación con Robert Castel", Archipiélago, núm. 29, Madrid, 1997a, pp. 42-55.

_ Las metamorfosis de la cuestión social. Una crónica del salariado, Barcelona, Piados, 1997b.

_- "Work and usefulness to the world", International Labour Review, vol. 135, núm. 6, New York, febrero-marzo de 1996, pp. 15-622.

— Les metamorphoses de la question sociale, Une chronique du salariat, Paris, Gallimard, 1995a.

-, "De la exclusión como estado a la vulnerabilidad como proceso", Archipiélago, núm. 21, Madrid, 1995b, pp. 27-36.
Cortina, Adela, Ciudadanos del Mundo. Hacia una teoría de la ciudadanía, Madrid, Alianza Editorial, 1998.

Chabrun, Laurent y Romain Rosso,"93 le No 1 de la violence”, en L'Express International, núm. 2836, Paris, 2005, pp. 30-34.

Chossudovsky, Michel, Guerra y Globalización. Antes y Después del XI/X/MmI, México, Siglo xxi, 2002a.

- Globalización de la pobreza y nuevo orden mundial, México, UNAM-Siglo XXI Editores, 2002b.

Crozier, Michel, Estado modesto, Estado moderno. Estrategia para el cambio, México, FCE, 1995.

Dandurand, Pierre, "La question sociale. Réflexions en marge de ún ouvrage de Pierre Rosanvallon", en Sociologie et Sociétés, Paris, 1996, pp. 189-198.

Dahrendorf, Ralf, La cuadratura del círculo. Bienestar económico cohesión social y libertad política, México, FCE (Cuadernos de la Gaceta 96), 1996.

—_ "Ciudadanía y sociedad civil: desafíos actuales de la democracia", en Reinhard Friedmann (coordinador), Democracia y sociedad civil, Bogotá, Materiales de Formación Liberal 4, Fundación Friedrich Naumann, 1995.

- Ley y Orden, Madrid, Editorial Civitas, 1994.

_- El nuevo liberalismo, México, Rei, 1993.

-, Oportunidades vitales. Notas para una teoría social y política, Madrid, EspasaCalpe, 1983.

Dixon, Keith, Les évangélistes du marché, Paris, Rasisons D'Agir Editions, 1998.

Donzelot, Jacques, L'invention du social. Essai sur le déclin des passions politiques, Paris, Éditions du Seuil, 1994.

Dubet, Francois, Les inégalités multipliées, Paris, Éditions de l'Aube, 2000.

Durkheim, Emile, La división del trabajo social (vols. 1 y 2), Madrid, Obras Maestras del Pensamiento Contemporáneo 46 y 47, Planeta-Agostini, 1993.

Esping-Andersen, Gösta, Fundamentos sociales de las economías postindustriales, Barcelona, Ariel, 2000.

_ Los tres mundos del Estado del bienestar, Valencia, Ediciones Alfons El Magnánim- Institució Valenciana D’Estudis i Investigació, 1993. 
Fitoussi, Jean-Paul y Pierre Rosanvallon, $L a$ nueva era de las desigualdades, Buenos Aires, Manantial, 1997.

Giddens, Anthony, La estructura de clases en las sociedades avanzadas, Madrid, Alianza Editorial, 1996.

Girola, Lidia, Las instituciones y el problema del poder en la obra de Talcott Parsons, México, Cuaderno 2 Teoría Sociológica y Modernidad, Facultad de Ciencias Políticas y Sociales-unAm, 1996.

Gowan, Peter, “¿Un nuevo paradigma políticodemocrático?", en Revista Internacional de Filosofia Política, núm. 17, Madrid, UAM-IUND, 2001, pp. 47-75.

Guerrero, Omar, Del Estado gerencial al Estado cívico, México, Universidad Autónoma del Estado de México-Miguel Ángel Porrúa, 1999.

Habermas, Jürgen, Problemas de legitimación en el capitalismo tardio, Buenos Aires, Amorrortu Editores, 1989.

Honneth, Axel, "Concepciones de la sociedad civil”, en Archipiélago, núm. 24, Madrid, 1996, pp. 47-54.

Keane, Jhon, La vida pública y el capitalismo tardio, México, Alianza Editorial, 1992.

Lechner, Norbert, "El capital social como problema cultural", Revista Mexicana de Sociología, vol. 64, núm. 2, México, IISUNAM, abril-junio de 2002, pp. 91-109.

Luhmann, Niklas, Teoría política en el Estado de bienestar, Madrid, Alianza Editorial, 1993.

Marcuse, Peter, El lenguaje de la globalización, S/L, Mimeo, 2001.

Macpherson, C.B., Ascenso y caída de la justicia económica y otros ensayos, Buenos Aires, Manantial, 1991.

Marramao, Giacomo, Lo politico y las transformaciones, México, Siglo xxi, 1982.

Marshall, T.H., "Ciudadanía y clase social", en T.H. Marshall y Tom Bottomore, Ciudadanía y clase social, Madrid, Alianza Editorial, 1998.

Mergier, Anne Marie, "Juventud desesperada", en Proceso, núm. 1534, México, 2006, pp. 54-59.

Mingione, Enzo, "Urban Poverty in the Advanced Industrial World: Concepts, Analysis and Debats", en Enzo Mingione (editor), Urban Poverty and the Underclass. A Reader, New York, Blackwell Publishers, 1996.
, Las sociedades fragmentadas. Una sociología de la vida económica más allá del paradigma del mercado, Madrid, Ministerio de Trabajo de Seguridad de España, 1993.

Montes, Pedro, Golpe de estado al bienestar. Crisis en medio de la abundancia, Barcelona, Icaria, 1996.

Nun, José, Marginalidad y exclusión social, Buenos Aires, FCE, 2001.

O'Connor, James, La crisis fiscal del Estado, Barcelona, Ediciones Península, 1981.

Offe, Claus, "La abolición del control del mercado y el problema de la legitimidad", Rudolf Sonntag y Héctor Valecillos, El Estado en el capitalismo contemporáneo, México, Siglo XXI Editores, 1999.

-, Partidos políticos y nuevos movimientos sociales, Madrid, Editorial Sistema, 1996.

, La gestión política, Madrid, Ministerio de Trabajo y Seguridad Social, 1992.

-, Contradicciones en el Estado de bienestar, México, CNCA-Alianza Editorial, 1990.

-,El Estado social y el cambio político", Política (suplemento), El Nacional, 25 de mayo de 1989, México, pp. 6-8.

- Disorganized Capitalism, Contemporary Transformations of Work and Politics, Londres, мIт-Press, 1985.

Oppenheimer, Walter, "Blair advierte de que el Estado de bienestar no es un saco sin fondo", www.elpais.es, 11 de junio de 2002.

Paugam, Serge, Nouvelles Precarites, Mimeo, Paris, 2000.

Pérez Ochoa, Isabel, "El libre mercado, ineficaz ante la pobreza", www.mileniodiario.com, 12 de enero de 2001.

Pico, Josep, Teorías sobre el Estado de bienestar, Madrid, Siglo XXI, 1990.

Polanyi, Karl, La Gran Transformación. Los Orígenes Políticos y Económicos de Nuestro Tiempo, México, FCE, 2003.

Procacci, Giovanna, "Ciudadanos pobres, la ciudadanía social y la crisis de los Estados de bienestar", en Soledad García y Steven Lukes (compiladores), Ciudadanía: justicia social, identidad y participación, Madrid, Siglo XxI, 1999.

Putnam, Robert, Making Democracy Work, Princeton, Princeton University Press, 1993.

Rosanvallon, Pierre, La nueva cuestión social, Buenos Aires, Manantial, 1995a. 
La crisis del Estado providencia, Madrid, Editorial Civitas, 1995b.

, Le libéralisme économique. Histoire de l'idée de marché, Paris, Éditions du Seuil, 1989.

Sandoval Ballesteros, Irma Erendira, "Intervencionismo neoliberal y desregulación financiera: evolución institucional del sector bancario en México", Revista Mexicana de Sociología, núm. 3, México, julio-septiembre de 2005, IIS-UNAM, pp. 593-631.

Schnapper, Dominique, "The European Debate on Citizenship", Daedalus, vol. 126, núm. 3, Londres, julio-agosto de 1997, pp. 199222.

Scott, John, "Seguridad social y desigualdad en México: de la polarización a la universalidad”, Bienestar y Política Social, vol. 1, núm 1, enero-marzo de 2005, pp. 59-82.

Sennett, Richard, La corrosión del carácter. Las consecuencias personales del trabajo en el nuevo capitalismo, Barcelona, Anagrama, 2000.

Silver, Hilary, "Social exclusion and social solidarity: Three Paradigms", International Labour Review, vol. 133, núms. 5-6, Nueva York, 1994, pp. 531-578.

Simmel, Georg, Sobre la individualidad y las formas sociales. Escritos escogidos, Buenos Aires, Universidad Nacional de Quilmes, 2001.

Székely, Miguel, "Introducción”, Miguel Székely (coordinador), Desmitificación y nuevos mitos sobre la pobreza, México, Miguel Ángel Porrúa-CIESAS-SEDESOL-ANUIES, 2005.
Tezanos, José Félix, La democracia incompleta. El futuro de la democracia posliberal, Madrid, Biblioteca Nueva, 2002.

Therborn, Göran, "Vida y tiempos del socialismo", Etcétera, núm. 13, México, 2 de abril de 1992, pp. 17-20.

Tilly, Charles, La desigualdad persistente, Buenos Aires, Manantial, 2000.

Tocqueville, Alexis, La democracia en América, Madrid, Ediciones Guadarrama, 1969.

Tortosa, José María, El juego global. Maldesarrollo y pobreza en el capitalismo mundial, Barcelona, Icaria, 2001.

Touraine, Alain, Producción de la sociedad, México, Instituto Francés para América Latina-Instituto de Investigaciones SocialesUNAM, 1995.

-, Igualdad y diversidad. Las nuevas tareas de la democracia, México, FCE, 2000.

Urry, Jhon, "Globalization and Citizenship", Journal of World-Systems Research, vol. 5, núm. 2, abril-junio de 1999, Nueva York, pp. 311-324.

Wallerstein, Immanuel, The insurmountable contradictions of liberalism, México, Coordinación de Humanidades-unAm (col. El Mundo Actual: Situación y Alternativas) 1996.

Wieviorka, Michel, "Sociologie Postclassique ou Déclin De La Sociologie?", Cahiers Internationaux de Sociologie, vol. 57, Paris, 2000, pp. 5-35.

Wirth, Louis, "El urbanismo como modo de vida", Mario Bassols (compilador), Antología de sociología urbana, México, UNAM, 1988. 